\title{
Pazarlamama Kavramı ve Gençlerin Gıda Tüketim Tercihleri Üzerine Bir Araştırma (De-marketing and A Research on Food Consumption Preferences of Young People )
}

\author{
İlknur AYAR \\ a Meslek Yüksekokulu, Çankırı Karatekin Üniversitesi, Çankırı, Türkiye. ilknurkilic37@gmail.com
}

\begin{tabular}{|c|c|}
\hline MAKALE BİLGİsİ & ÖZET \\
\hline Anahtar Kelimeler: & \multirow{6}{*}{$\begin{array}{l}\text { Amaç - Artan iş yükü, stres faktörleri, çalışma yaşamındaki değişiklikler, hızlı yaşam tarzları, } \\
\text { yiyecek endüstrisindeki gelişmeler ve hızlı tüketime yönelimlerin yol açtı̆̆, özellikle gençlerin } \\
\text { gıda alımlarındaki değişiklikler, son birkaç yılda gözlemlenen gençlik dönemi obezitesindeki ve } \\
\text { sağllksız beslenmeye dayalı sağlık sorunlarındaki artışı önemli sebepleri arasındadır. Bununla } \\
\text { birlikte günümüzde gıda pazarlamasının, dünyadaki gençlerin sağlıklarını, giderek ve olumsuz } \\
\text { yönde etkilediği pek çok çevre tarafından kabul edilmektedir. Sosyal amaçlı demarketing } \\
\text { uygulamaları gıda endüstrisindeki pazarlama uygulamalarına bazı sınırlılıklar getirmektedir. } \\
\text { Bu araştırmanın amacı, genç nüfusun sağlığını tehdit eden gıda tüketimine ilişkin sosyal amaçlı } \\
\text { demarketing kavramı çerçevesinde bir kavramsal temel oluşturmaktır. }\end{array}$} \\
\hline Gıda Tüketimi & \\
\hline Sağlıklı Gıda Tercihi & \\
\hline & \\
\hline Demarketing & \\
\hline Pazarlamama & \\
\hline Gönderme Tarihi 5 Ocak 2019 & \multirow{3}{*}{$\begin{array}{l}\text { Yöntem - Bu araştırma bilimsel araştırma türlerinden olan, mevcut verileri bir araya getirip, } \\
\text { mevcut durumu ortaya koyarak birincil verilere ulaşmak amacıyla görüşme, anket, deneysel } \\
\text { yöntemler üzerine kurulan bir açıklayıcı araştırmadır. Araştırmada birincil verilere ulaşmak } \\
\text { amacıyla nicel yaklaşımlardan biri olan anket tekniğinden yararlanılmıştır. }\end{array}$} \\
\hline Revizyon Tarihi 10 Mart 2019 & \\
\hline Kabul Tarihi 22 Mart 2019 & \\
\hline $\begin{array}{l}\text { Makale Kategorisi: } \\
\text { Araştırma Makalesi }\end{array}$ & $\begin{array}{l}\text { Bulgular - Araştırma sonucunda gençlerin yemek yeme alışkanlıkları ile diyet ve kilo kontrolü } \\
\text { davranışları arasında anlamlı bir ilişki bulunmuştur. Aynı zamanda araştırma sonuçları } \\
\text { gençlerin besin içeriklerine yönelik etiket uygulamalarını dikkate alma durumlarının, ne } \\
\text { yediğinin farkında olma ve bilinçli besin tüketimi alışkanlıkları ile doğru orantılı olarak } \\
\text { değiştiğini göstermiştir. Tüm boyutlarda erkek katılımcıların kadın katılımcılardan daha pozitif } \\
\text { tutuma sahip oldukları gözlenmiştir. }\end{array}$ \\
\hline & $\begin{array}{l}\text { Tartışma - Gençlerin artık, daha fazla yemek yememe, sağlıklı beslenme, şeker, tuz ve yağ } \\
\text { tüketimini azaltma, sağlıklı diyet takip etme, gibi bakımlardan kendilerini sorgular hale } \\
\text { geldikleri ortaya çımıştır. Bu nedenle gıda üreticilerinin ve perakendecilerin okuması ve } \\
\text { anlaşılması kolay beslenme etiketlemelerini geliştirmeleri halinde ürünlerini standart beslenme } \\
\text { etiketi bulunan ürünlere göre avantajlı kılabilir. }\end{array}$ \\
\hline
\end{tabular}

\begin{tabular}{ll}
\hline ARTICLE INFO & ABSTRACT \\
\hline Keywords: & $\begin{array}{l}\text { Purpose - Increased workload, stress factors, changes in working life, rapid lifestyles, changes } \\
\text { in food industry, and trends in fast food consumption, especially in young people's food } \\
\text { purchases, are among the important reasons for the increase in health problems based on } \\
\text { unhealthy nutrition and youth obesity in the last few years. However, it is accepted by many } \\
\text { environments that food marketing affects the health of young people in the world gradually and } \\
\text { negatively. Social-purpose demarketing practices bring some limitations to marketing practices } \\
\text { in the food industry. The aim of this study is to provide a conceptual basis for the demographics } \\
\text { of social purposes related to food consumption that threatens the health of the young } \\
\text { pe-marketing }\end{array}$ \\
$\begin{array}{l}\text { pepulation. } \\
\text { Design/methodology/approach - This research is an explanatory research which is based on } \\
\text { interviews, questionnaires and experimental methods in order to reach the primary data by } \\
\text { gathering the existing data and presenting the current situation. In order to reach primary data, } \\
\text { one of the quantitative approaches was used. }\end{array}$ \\
$\begin{array}{l}\text { Received 5 Junuary 2019 } \\
\text { Accepted 22 March 2019 }\end{array}$ \\
$\begin{array}{l}\text { Findings - A significant relationship was found between young people' eating habits and diet } \\
\text { and weight control behaviors. The fact that young people take into account labeling practices for } \\
\text { their nutritional content shows that they are aware of what they eat and that they are changing } \\
\text { in direct proportion to the habits of conscious food consumption. } \\
\text { Desearch Article }\end{array}$ \\
$\begin{array}{l}\text { Discussion - Young people no longer eat more food, healthy eating, sugar, salt and fat } \\
\text { consumption, healthy diet, such as follow-up, have become themselves questions. Therefore, if } \\
\text { food producers and retailers develop easy to read and understand nutritional labeling, they can } \\
\text { make their products more advantageous than products with a standard diet label. }\end{array}$
\end{tabular}




\section{Giriş}

Pazarlama, kişisel ve örgütsel amaçlara ulaşmayı sağlayacak mübadeleleri gerçekleştirmek üzere, fikirlerin, malların ve hizmetlerin geliştirilmesi, fiyatlandırılması, tutundurulması ve dağıtılmasına ilişkin planlama ve uygulama sürecidir (Mucuk, 2001: 4). Sosyal amaçları gerçekleştirebilmek amacıyla pazarlama uygulamalarının kullanılmasını ifade eden sosyal pazarlama ise, pazarlamamayı ifade eden de-marketing kavramının ortaya çıkma durumlarından birinin temelini oluşturmaktadır (Memiş, 2017: 774). Genel bir müşteri kitlesinin ya da belirli bir grup müşterinin geçici ya da kalıcı olarak talep etmekten uzaklaştırması, satın alma isteğinin azaltılmasına yönelik faaliyetler bütünü olarak tanımlanan pazarlamama uygulamalarının ilk örnekleri, sigara içme oranlarının azaltılması ve sağlık sektöründeki harcamaların düşürülmesi amacıyla uygulanmıştır. Toplumsal faydanın gözetildiği anlarda ortaya çıkan bu durum, toplum sağlığının korunması, sigara kullanımının azaltılması, sağlık harcamalarının düşürülmesi gibi pek çok konuda gündeme gelmektedir.

Günümüzde hazır gıda pazarlamasının, dünyadaki gençlerin sağlıklarını, giderek ve olumsuz yönde etkilediği pek çok çevre tarafından kabul edilmektedir (Freeman, Kelly, Vandevijvere ve Baur, 2016: 954). Ortaya konulan kanıtlar, artan kalori alımının, gençlerin sağliklarını olumsuz etkilediğini işaret eden güçlü bir açıklama olduğunu göstermektedir. Kalori tüketimini artıran çevresel faktörler, obezitenin potansiyel nedenleri olarak nitelendirilirken, yüksek kalorili alımın en iyi bilinen itici güçlerinden biri pazarlama uygulamalarıdır (Scully, Dixon ve Wakefield, 2009). Ayrıca yetişkinlere kıyasla gençler, pazarlama ve markalamaya karşı daha savunmasız durumdadırlar. Günümüze kadarki süreçte gençlere yönelik yiyecek ve içecek pazarlaması halk sağlığı açısından ve gıda tüketim alışkanlıkları veya kilo durumu üzerindeki etkileri açısından değerlendirilmemiştir (Nelson vd., 2008). Halbuki pazarlama anlayışı, riskli veya sağlıksız ürünlerin pazarlanmasının olası zararlarına karşı yeterli bir savunma değildir. Buna karşın, ergen ve genç erişkinlerin sağlıksız yiyecek ve içecek pazarlamasına maruz kalmasını etkili bir şekilde azaltmak için, sosyal ve mobil medya, spor ve etkinlik sponsorluğu ve okullarda da dahil olmak üzere tüm medya aracılığıla kısıtlamak üzere kapsamlı hükümet düzenlemeleri gereklidir. Örneğin, alkol markalarının spor faaliyetlerini desteklemesine izin verilmediği Fransa'daki alkol pazarlaması kısıtlama yaklaşımına benzer uygulamalar geliştirilebilir (Freeman, Kelly, Vandevijvere ve Baur, 2016: 954).

Ürün bakımından gıda ürünlerine yönelik bu pazarlamama uygulamaları; sınırlı mal ve hizmet sunumu ya da bazı ürünlerin pazara ya da seçilen kişilere sunulmaması, ikame ürünlerin ön plana çıkarılması, yüksek fiyat belirleme, sınırlı dağıtım (mekanların kısıtlanması veya ürüne ulaşımın kontrole tabi tutulması) ve tanıtım gerçekleştirme gibi şekillerde olabilmektedir. Gıdalardaki yağ, şeker, tuz gibi sağlı̆̆ tehdit eden öğeleri çocuklara kısıtlamak da dahil olmak üzere, gıda üreticilerinin genç nüfusa yönelik mevcut pazarlama baskısını azaltmak gibi çeşitli müdahaleler günümüz gerekliliklerindendir. Bu müdahaleler gıda ürünlerinin pazarlanmaması bakış açısıyla bu araştırmanın kavramsal kısmının temelini oluşturmuştur, konu çeşitli yönlerden incelenmiştir. Ayrıca üniversite öğrencilerinin gıda seçim tercihleri nicel araştırma yöntemlerinden anket tekniği ile birincil verilere erişilmiştir. Bu araştırma kapsamında genç tüketicilerin mevcut gıda seçimleri ve beslenme alışkanlıkları ile ilgili davranış ve tutumlarını ortaya koymak, gıda tüketim tercihlerini belirlemek üzere tüketicilere uygulanan anketler ile toplanılan veriler çeşitli istatistiksel yöntemlerle incelenerek, sonuçlar yorumlanmıştır. Bu sonuçlar neticesinde gıda ürünleri pazarlaması üzerine, tütünde olduğu gibi etiketler ve diğer uygulanan yöntemler vasıtasıyla kısıtlayıcı düzenlemeler getirilmesi; sağlıksız yiyeceklerle ilgili tüm televizyon reklamlarının geç saatlerde yayınlanması; internette, sosyal medyada ve oyunlarda sağlığı tehdit eden yiyeceklerin reklamlarının kısıtlanması gibi çeşitli uygulamalar ile çocukların korunabileceği düşünceleri üzerine öneriler ortaya konulmuştur.

\section{Kavramsal Araştırma}

Pazarlamama kavramıyla ilgili çalışmalar çoğunlukla çevre sorunları, halk sağlı̆̆ı, turizm ve diğer yaygın talep gören mal ve hizmetlere yönelik pazarlamanın azaltılması (talebin azaltılması) uygulanmasına odaklanmıştır; ayrıca, fiyatlandırma, dağıtım, tutundurma ve talebi azaltmak için ürün sorunları gibi taktiksel yönlere pazarlama karmasının uygulanmasına odaklanmıştır (Cintrón vd., 2017: 79). Daha önceki araştırmalarda Demarketing (pazarlamama) kavramı ile ilgili daha çok tütün ve alkol gibi zararlı maddelerin pazarlamama faaliyetlerine odaklanılmıştır (Lepisto, 1983; Cui ve Choudhury, 2003; Lee, Cutler ve Burns, 2004; Lefebvre ve Kotler, 2011; Yang, Schaninger ve Laroche, 2013). Lepisto (1983), güçlü talepleri olan ancak 
insan sağlığına ters olarak değerlendirilen (sigara gibi) ürünlere yönelik pazarlamama kavramına değinmiştir. Yazara göre pazarlamama uygulamasında bu ürünler pazardan kaldırılmazlar ancak tüketicilerin ikame maddeleri göz önünde bulundurmaları şiddetle önerilir. Lefebvre ve Kotler'e (2011) göre, sosyal pazarlama "sigarayı bırakma", "uyuşturucuya hayır deme" ve "daha fazla egzersiz yapma" gibi kampanyaları içeren pazarlamama kavramının odağını oluşturmuştur. Post ve Baer (1979), insan sağlığına uygun olmayan ürünlerin pazarlanmamasının önemini tartışmışır. Türkiye'de ise pazarlamama kavramına ilişkin çok az sayıda akademik çalışmaya rastlanmıştır. Bu çalışmalardan bazıları, genel olarak demarketing (pazarlamama) kavramına değinmiş (Altınay ve Sert, 2012), sürdürülebilirlik ile demarketing ilişkisini ele almış (Onaran, 2017), Bozacı (2016) ise, bankacılık hizmetlerinde tüketicilerin demarketing uygulamalarına yönelik tutumlarını incelemiştir.

Sağlıksız gıda ürünlerine yönelik pazarlamama uygulamaları açısından Türkiye'deki çalışmalara rastlanılmamıştır. Pazarda göreceli olarak azalan-artan taleple baş edebilme amacıyla ortaya çıkan demarketing kavramı önemli bir pazarlama fonksiyonudur. Çünkü pazarlamacılar için talep azlığı ile baş edebilmek kadar talep fazlasıyla da baş edebilmek bir sorundur (Kotler ve Levy, 1971: 75). Demarketing kavramı temelinde uzun vadeli müşteri ilişkilerine zarar vermeden toplam talebi veya belirli talep sınıflarını arz seviyesine indirmenin yollarını bulma maksadını taşımıştır. Kotler ve Levy, (1971: 75) demarketing kavramını 'genel olarak müşterileri ya da belirli bir müşteri sınıfını geçici ya da kalıcı olarak kaynaktan yoksun bırakmaya yönelten bir pazarlama stratejisi olarak tanımlamışlardır.

Kotler ve Levy (1971: 75) üç tür pazarlamama (demarketing) türünü tanımlamıştır, genel demarketing, bir şirketin toplam talep seviyesini daraltmak istediğinde yaptığı demarketing stratejileri, seçici demarketing, bir şirket belirli müşteri sınıflarından gelen talebi engellemek istediğinde yaptığı demarketing stratejileri, görünürde pazarlamama bir şirket, karşıt etkinin gerçekleşmesi umuduyla, demarketing stratejilerini uygulayarak, daha fazla müşteri istemediğinin ortaya çıkmasını sağlar. Ürünü insanlar için daha da cazip hale getirmeyi umar. Demarketing stratejisi, hem pazar yönlü hem de sosyal yönlü uygulamaları barındırır. Bu bakımdan toplumsal pazarlama ile ilişkilendirilen kavram, doğal çevre, kıt kaynaklar ve sağlıklı yaşamın önem kazanmasına bağlı olarak incelenmektedir. Bu noktada seçici demarketing faaliyetlerinin üzerinde durmak gerekmektedir (Bozac1, 2016: 71).

Seçici demarketing stratejisini uygulayan işletmeler, ürün ya da hizmetlere olan toplam talebin tümünü azaltmak istemezler, sadece pazarın belirli bölümlerinden gelen talebe yönelik olarak azaltıcı önlemler almak isteyebilirler (Altınay ve Sert, 2012:72). Tütün ve alkol örneği, dünya çapında kullanılan en popüler seçici pazarlamama taktikleri arasındadır.

Son zamanlarda halk sağlığı, demarketing uygulamaları için bir bağlam olarak ele alınmıştır; Örneğin, bazı akademisyenler, toplum sağlığını teşvik etmeye odaklanmışlardır (Haq, Medhekar, ve Ferdous, 2011). Bir takım araştırmacı ise demarketing uygulamalarının insanların tütün veya sigara içmeyi bırakmasına yardımcı olabileceğini öne sürmüştür (Lee, Cutler ve Burns, 2004; Moore, 2005; Bourdeau, Brady ve Cronin, 2006; Barbara, 2008; Inness, Barling, Rogers ve Turner, 2008; Hassan, Shiu, Walsh ve Hastings, 2009; Gundlach, Bradford ve Wilkie, 2010; Salem, 2010; Gallopel-Morvan, Jacques, Mathias ve Pino, 2012; Baporikar ve Fotolela, 2017).

Moore (2005), bu tür çabaların etkililiğine ilişkin yaptığı değerlendirmede, sigara içme davranışları üzerinde derin bir etkiden bahsetmiştir. Yine bir kısım araştırmacı gençlerin tütün ve alkol kullanımını azaltmaya ve ailelere bu konuda nasıl yardımcı olabileceği üzerine demarketing kavramını tartışmışlardır (Beeton ve Benefield, 2002; Yang, Schaninger ve Laroche, 2013). Alkol ve tütün ile aynı kategoriye, yüksek yağlı hızlı (fastfood) yiyecekler ve şekerli gazlı içecekler gibi sağlıksız olarak ifade edilebilecek ürünler de eklenebilir.

Son zamanlarda gençlere yönelik yiyecek pazarlaması faaliyetleri gençlerin sağlıklarını giderek etkilemekte ve bu nedenle pazarlama baskısını azaltmak için nüfus sağlığına yönelik müdahaleler gündeme gelmektedir. Bu kısıtlamalar çeşitli şekilde yapılmaktadır. Örneğin, Dünya Obezite Federasyonu, diğer halk sağlığı teşkilatları ile birlikte, gıda ürünlerinde gidilmesi gereken düzenlemeleri önermektedir. Bu önerilerden biri, zayıf beslenme kalitesindeki ürünler üzerine tütünde olduğu gibi grafik uyarı etiketlerinin uygulanabileceği şeklindedir. Araştırmacılar tarafından getirilen diğer bir öneri sağlıksız yiyecekler için televizyon reklamlarını saat 21.00 'a kadar (çocuklar için uygun olmayan programların yayınlanabileceği zamana kadar) kısıtlayarak küçük çocukları korumaya çalışmaktadır (Elliott, 2017: 430). Araştırmacılar ayrıca, fast food ve 
şekerli gazlı içeceklerin reklamlarını Facebook gibi sosyal medyadaki gençlere (18 yaşın altında) yasaklamalarını da tavsiye etmişlerdir (Williams, 2013).

Obezite ile mücadele etmek için büyük çaba sarf eden halk sağlı̆̆ı örgütleri, beslenme ürünlerinin etiketlemesinin sağlıklı beslenme davranışının geliştirilmesinde vazgeçilmez bir araç olduğunu vurgulamaktadırlar. Bu durum gida ürünleri üzerinde verilen bilgilerin toplumda sağliklı beslenme davranışının geliştirilmesi için doğru ve açık bir şekilde verilmesi gerektiğini göstermektedir.

Bir kısım araştırmacı ise, özellikle çocukları daha fazla yemeye teşvik eden ya da gördüklerinde etkilenerek daha fazla yemek istediklerini belirttikleri sağlıksız yiyeceklere yönelik internette veya diğer reklam alanlarındaki reklamların düzenlenmesinin gerektiğini vurgulamışlardır (Folkvord vd., 2015). Ayrıca, demarketing stratejisi, sosyal normları değiştirmek için diğer taktiklerle birlikte çalışmalıdır. Örnek olarak; tüketim vergileri, ihracat-ithalat vergileri veya dağıtım kısıtlamaları verilebilir.

\section{Yöntem}

$\mathrm{Bu}$ araştırma bilimsel araştırma türlerinden olan, mevcut verileri bir araya getirip, mevcut durumu ortaya koyarak birincil verilere ulaşmak amacıyla görüşme, anket, deneysel yöntemler üzerine kurulan bir açıklayıcı araştırmadır. Araştırmada birincil verilere ulaşmak amacıyla nicel yaklaşımlardan biri olan anket tekniğinden yararlanılmıştır.

Araştırmanın uygulama kısmında, genç tüketicilerin gıda seçimleri ve beslenme alışkanlıkları ile ilgili davranış ve tutumları tanımlamak, gıda tüketim tercihlerini belirlemek üzere tüketicilere gida tercihlerini belirlemek üzere 21 madde ve kişisel bazı özelliklerini belirlemek üzere 3 maddeden oluşan bir anket uygulanmıştır. Anket daha önceki araştırmalardan uyarlanmıştır (Lone, Pence, Levi, Chan ve Bianco-Simeral, 2009). Anket formunda yer alan ifadelere katılımcıların ne derecede katıldığını belirlemek üzere 5'li Likert tipi derecelendirme yapılmıştır. Buna göre ifadeler, "Kesinlikle Katılmıyorum (1)", "Katılmıyorum (2)", “Orta Düzeyde Katılıyorum (3)”, “Katılıyorum (4)”, “Tamamen Katılıyorum (5)” şeklinde puanlandırılmıştır.

Araştırmanın evrenini üniversite öğrencileri oluşturmaktadır. Çalışma evrenin tümüne bütçe, zaman ve ulaşamama gibi sebeplerden dolayı bir örneklem belirleme yoluna gidilmiştir. 1.000.000 kişi üzerindeki nüfus popülasyonlarında \%95 güven aralığında doğru sonuç elde edebilmek için gereken örnek sayısı 384 kişi ve üzeridir (Saunders, Lewis ve Thornhill, 2009: 219). Araştırma kapsamında bu örneklem sayısına ulaşmak amacıyla, geri dönüş oranları da göz önünde tutularak 500 adet anket formu dağıtılmış olup, bunlardan 432 adedi geri dönmüştür. Geri dönen formlardan araştırmada kullanımı uygun bulunmayan 22 tanesi araştırma dışında tutulmuş, 410 tanesi araştırmaya dahil edilmiştir.

Araştırma kapsamında oluşturulan hipotezler aşağıdaki gibidir:

$\mathrm{H}_{1}$ : Gıda tüketimi tercihleri cinsiyete göre anlamlı farklılık göstermektedir.

$\mathrm{H}_{2}$ : G1da tüketimi tercihleri barınma durumuna göre anlamlı farklılık göstermektedir.

H3: Gıda tüketimi tercihleri kilo durumuna göre anlamlı farklılık göstermektedir.

Araştırma kapsamında ölçeğin geçerliliğini ve güvenilirliğini belirlemek üzere iç tutarlılık analizleri, açıklayıcı ve doğrulayıcı faktör analizleri yapılarak model test edilmiştir. Analizler bilgisayar ortamında SPSS ve LISREL programları ile gerçekleştirilmiştir.

\section{Bulgular}

Öncelikle ölçeğin güvenilirlik analizi, ardından ölçeği karmaşık örüntülerinden ayrıştırarak elde edilen verilerin daha anlaşılır ve daha sade bir hale gelmesini sağlamak üzere kullanılan açıklayıcı faktör analizi, ardından açıklayıcı faktör analizi ile oluşturulan ölçeğin yapı geçerliğinin sağlanması ve doğrulanması amacıyla doğrulayıcı faktör analizi uygulanmıştır. Ölçeğin geçerlik ve güvenilirlik çalışmalarının ardından araştırma bulgularına yer verilmiştir.

Tablo 1'de ölçeğin güvenilirliğine yönelik sonuçlar yer almaktadır.

Tablo 1. Maddeler Düzeyinde Güvenilirlik Analizi Sonuçları 
İ. Ayar 11/1 (2019) 545-557

\begin{tabular}{|l|l|l|l|l|}
\hline & $\begin{array}{l}\text { Madde Silindiğinde } \\
\text { Ölçeğin Genel } \\
\text { Ortalaması }\end{array}$ & $\begin{array}{l}\text { Madde } \\
\text { Silindiğinde } \\
\text { Ölçeğin Alacă̆1 } \\
\text { Yeni Varyans }\end{array}$ & $\begin{array}{l}\text { Düzeltilmiş } \\
\text { Madde Toplam } \\
\text { Korelasyonu }\end{array}$ & $\begin{array}{l}\text { Madde } \\
\text { Silindiğinde } \\
\text { Ölçeğin Yeni C- } \\
\text { Alpha Değeri }\end{array}$ \\
\hline s1 & 45,0098 & 125,633 & 0,434 & 0,855 \\
\hline s2 & 45,7146 & 125,055 & 0,401 & 0,856 \\
\hline s3 & 45,0366 & 125,502 & 0,363 & 0,858 \\
\hline s5 & 44,6854 & 121,052 & 0,497 & 0,852 \\
\hline s10 & 44,6366 & 121,225 & 0,488 & 0,852 \\
\hline s11 & 44,3976 & 125,13 & 0,357 & 0,859 \\
\hline s12 & 44,7707 & 122,045 & 0,495 & 0,852 \\
\hline s13 & 45,2415 & 119,611 & 0,599 & 0,847 \\
\hline s14 & 44,8805 & 120,321 & 0,566 & 0,849 \\
\hline s15 & 44,1122 & 120,55 & 0,579 & 0,848 \\
\hline s16 & 44,4366 & 123,503 & 0,379 & 0,858 \\
\hline s17 & 44,9805 & 121,608 & 0,542 & 0,85 \\
\hline s18 & 45 & 119,374 & 0,601 & 0,847 \\
\hline s19 & 44,6341 & 117,519 & 0,585 & 0,847 \\
\hline s20 & 44,8561 & 121,444 & 0,515 & 0,851 \\
\hline s21 & 45,0463 & 123,086 & 0,427 & 0,855 \\
\hline
\end{tabular}

Tablo 1'de verilen, ölçeğe ilişkin madde analizi sonuçları incelendiğinde bir maddenin diğer maddelerle olan ilişkisinin 0,30'un altında olmamasının gerekliliğinden dolayı, 0,30'un altında olan 4,6,7,8,9 nolu maddeler ölçekten çıkarılmıştır. Ölçeğin Cronbach's Alpha kat sayısı 0,860 olarak bulunmuş, 0,70'ten büyük olduğu için güvenilirliğinin yüksek olduğu belirlenmiştir.

Ölçeğin maddeler düzeyinde güvenilirlik analizi sonuçlarına bakıldıktan sonra açıklayıcı faktör analizine geçilmiştir. Ölçeğin faktör analizine uygun olup olmadığını belirlemek üzere Bartlett's Küresellik Testi sonuçlarına bakılmış olup, değişkenler arasında ilişki bulunmuştur $(p<0,05, p=0,00)$. Örneklem sayısının faktör analizine uygun olup olmadığını belirleyen KMO değeri ise 0,60'ın üzerinde olması gerekmekte olup, analiz sonucunda KMO değerinin 0,86 olduğu gözlenmiştir. $\mathrm{Bu}$ durumda örneklem sayısının faktör analizine uygun olduğu sonucuna ulaşılmıştır.

Yapılan analiz sonucunda güvenilirlik analizi kapsamında 16 maddeye düşürülen ölçek binişik değerler ve amaca hizmet etmeyen değerler elenerek 14 maddeye düşürülmüştür. Tablo 2'de madde faktör yükleri bulunmaktadır.

Tablo 2'de ölçeğe ait açıklayıcı faktör analizi sonuçlarına yer verilmiştir.

Tablo 2. Ölçeğe Ait Açıklayıcı Faktör Analizi Sonuçları

\begin{tabular}{|c|c|c|c|}
\hline Faktörler & Maddeler & $\begin{array}{l}\text { Faktör } \\
\text { Ağırlıkları }\end{array}$ & $\begin{array}{l}\text { Faktör } \\
\text { Açılayıcıları }\end{array}$ \\
\hline \multirow[t]{5}{*}{ Faktör 1} & $\begin{array}{l}\text { Besin etiketlerini gıda seçimlerim için bir rehber olarak } \\
\text { kullanma alışkanlığım yok. }\end{array}$ & ,739 & \multirow[t]{5}{*}{20,674} \\
\hline & Sağlıklı yemekleri tercih etmek gibi bir alışkanlığım yok. & ,737 & \\
\hline & $\begin{array}{l}\text { Maliyeti düşük bile olsa daha sağlıklı yiyecek seçimi yapmak } \\
\text { gibi bir alışkanlığım yok. }\end{array}$ & ,715 & \\
\hline & $\begin{array}{l}\text { Sık sık yağ oranı yüksek veya karbonhidrat içerikli } \\
\text { yiyeceklerle besleniyorum. }\end{array}$ & 623 & \\
\hline & Yediğim yiyeceklerin kalori içeriğinin farkında değilim. & 611 & \\
\hline \multirow[t]{3}{*}{ Faktör 2} & Diyet yiyecekleri tercih etmiyorum. & ,776 & \multirow[t]{3}{*}{14,306} \\
\hline & $\begin{array}{l}\text { Besin etiketlerini gıda seçimlerim için bir rehber olarak } \\
\text { kullanma alışkanlığım yok. }\end{array}$ & 644 & \\
\hline & $\begin{array}{l}\text { Kalori hesabı yapmadan ve kilomu takip etmeden yemek } \\
\text { yemekten hoşlaniyorum. }\end{array}$ & 629 & \\
\hline
\end{tabular}


İ. Ayar 11/1 (2019) 545-557

\begin{tabular}{|c|c|c|c|}
\hline & Ne yiyeceğim konusunda fazla düşünmem. &, 500 & \\
\hline \multirow[t]{3}{*}{ Faktör 3} & Çoğu zaman gereğinden fazla yemek yerim. & 727 & \multirow[t]{3}{*}{12,196} \\
\hline & $\begin{array}{l}\text { Sağlıklı gida seçenekleri yerine benim için porsiyon boyutu } \\
\text { daha önemlidir. }\end{array}$ & 645 & \\
\hline & $\begin{array}{l}\text { Büyük porsiyonlarla hizmet veren restoranlarda yemeyi tercih } \\
\text { ederim. }\end{array}$ & ,639 & \\
\hline \multirow[t]{2}{*}{ Faktör 4} & Sık sık Fast-Food restoranlarında yemek yerim. & ,789 & \multirow[t]{2}{*}{11,982} \\
\hline & Ne yediğimin farkında olmadan yemek yerim. & ,736 & \\
\hline \multicolumn{3}{|l|}{ Toplam } & 59,158 \\
\hline \multicolumn{3}{|c|}{ Cronbach's Alpha } & ,845 \\
\hline \multicolumn{3}{|l|}{$\mathrm{Sd}$} & 91 \\
\hline \multicolumn{3}{|l|}{$\mathrm{p}$} & 0,000 \\
\hline
\end{tabular}

Açıklayıcı faktör analizi sonucunda 16 maddelik ölçek 4 faktör altında toplanmıştır. Bu faktörler toplam varyansın \%59,158'ini açıklamaktadır. Faktörlere ait maddeler incelendiğinde; 1. Faktör altında 5 madde toplanmış ve bu faktör "Besin içeriklerine göre sağlıklı gıda tüketimi" olarak adlandırılmıştır. 2. Faktör altında 4 madde toplanmış ve bu faktör "Kilo takibi ve diyet" olarak adlandırılmıştır. 3. Faktör altında 3 madde toplanmıs, bu faktör "Porsiyon boyutu" olarak adlandırılmıştır. Son faktör altında ise 2 madde toplanmış olup, bu faktör "Yemek yeme davranışı" olarak adlandırılmıştır.

Açıklayıcı faktör analizi ile oluşturulan ölçeğin yapı geçerliğinin sağlanması ve doğrulanması amacıyla doğrulayıcı faktör analizi uygulanmıştır. Doğrulayıcı faktör analizi, gözlenen değişkenlerin gizil değişkenleri açıklama kabiliyetlerini ortaya koymayı amaçlayan bir tür yapısal eşitlik modellemesi olarak tanımlanmaktadır. Doğrulayıcı faktör analizi gözlenen ve gizil değişkenler arasındaki ilişkiyi inceleyerek, önceden faktör yapısı belirlenmiş bir ölçeğin değişkenlerinin bu yapı ile uyum derecesini ortaya koyar ve modelin test edilmesini sağlar.

Tablo 3. Ölçeğe Ait Doğrulayıcı Faktör Analizi Sonuçları

\begin{tabular}{|c|c|c|c|c|}
\hline Faktör & Madde No & Standartlaştırılmış Yükler & $\mathrm{R}^{2}$ & $\mathrm{t}$ \\
\hline \multirow{5}{*}{ Faktör 1} & 1 & 0,56 & 0,31 & 11,24 \\
\hline & 2 & 0,72 & 0,51 & 15,39 \\
\hline & 3 & 0,69 & 0,47 & 14,71 \\
\hline & 4 & 0,65 & 0,42 & 13,46 \\
\hline & 5 & 0,71 & 0,50 & 15,10 \\
\hline \multirow{4}{*}{ Faktör 2} & 1 & 0,59 & 0,34 & 11,45 \\
\hline & 2 & 0,49 & 0,24 & 9,13 \\
\hline & 3 & 0,56 & 0,31 & 10,73 \\
\hline & 4 & 0,67 & 0,44 & 13,14 \\
\hline \multirow{3}{*}{ Faktör 3} & 1 & 0,48 & 0,23 & 8,65 \\
\hline & 2 & 0,66 & 0,43 & 11,95 \\
\hline & 3 & 0,53 & 0,28 & 9,64 \\
\hline \multirow{2}{*}{ Faktör 4} & 1 & 0,68 & 0,46 & 11,37 \\
\hline & 2 & 0,62 & 0,38 & 10,58 \\
\hline
\end{tabular}

Tablo 3 incelendiğinde, ölçeğin AFA sonucunda elde edilen faktör yapısının madde istatistikleri açısından DFA bulguları ile de doğrulandığı söylenebilir. Öte yandan çoklu korelasyon karesine ilişkin değerler $\left(\mathrm{R}^{2}\right)$ 0,23- 0,51 arasında değişmektedir. Bu bağlamda da R2 değerinin orta bağlamda olduğu ifade edilebilir.

Şekil 1'de modele Path diyagramı incelendiğinde modele ait uyum indeksleri istenilen aralıkta olduğundan herhangi bir modifikasyona gerek duyulmamıştır. 


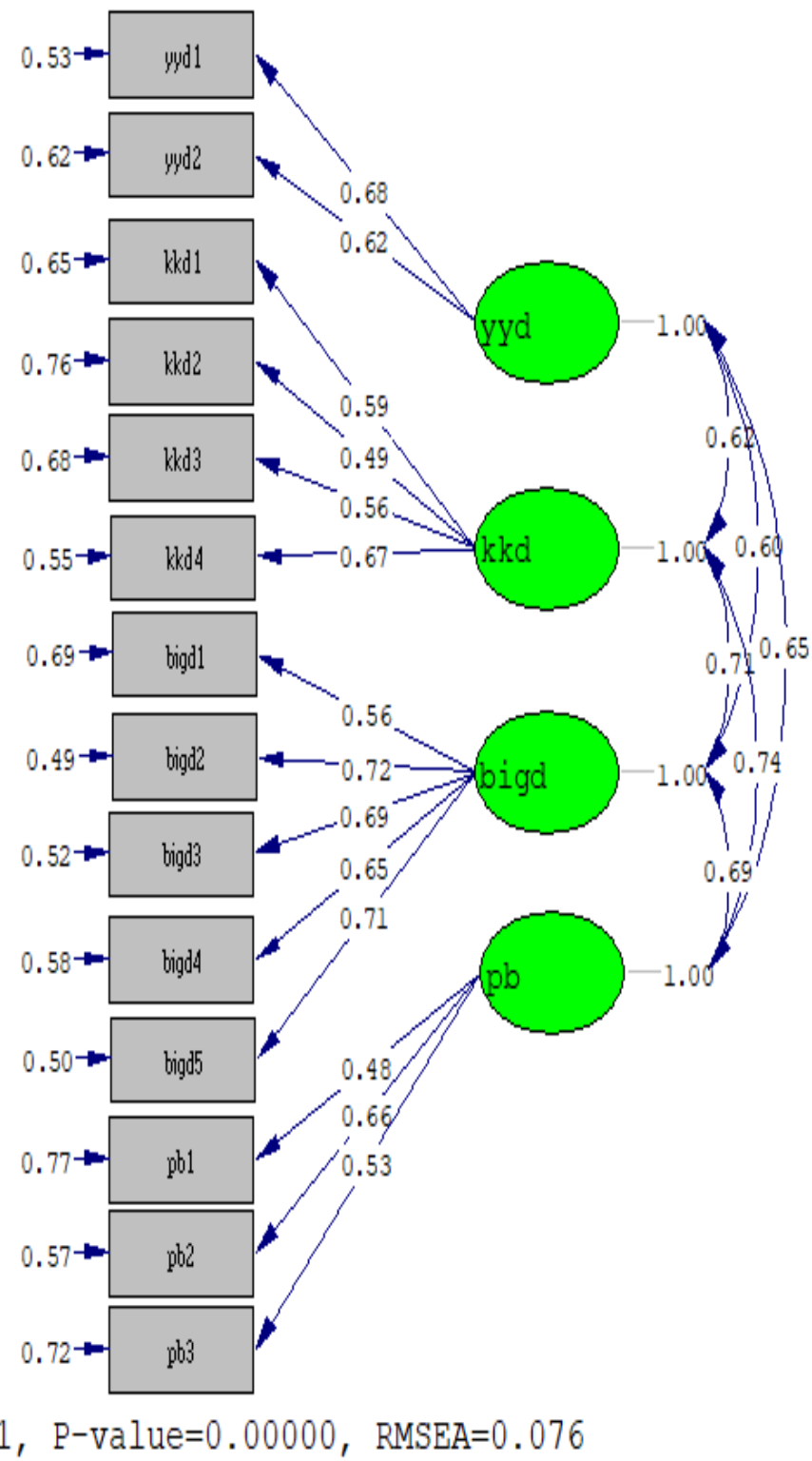

Şekil 1. Doğrulayıcı Faktör Analizi Path Diyagramı

YYD: Yemek Yeme Davranışı, KKD: Kilo Kontrolü Davranışı, BİGD: Besin İçeriğine Göre Gıda Tüketimi Davranışı, PB: Porsiyon Boyutu

Yapılan doğrulayıcı faktör analizi sonucunda yemek yeme davranışı boyutunun kilo kontrolü davranışı ile arasındaki ilişkinin miktarı 0,62, besin içeriğine göre gıda tüketimi ile arasındaki ilişkinin miktarı 0,60, porsiyon boyutu tercihi ile arasındaki ilişkinin miktarı 0,65 olarak gözlenmiştir. Kilo kontrol davranışı ile besin içeriğine göre gıda tüketimi davranışı arasındaki ilişkinin miktarı 0,71, porsiyon boyutu tercihi arasındaki ilişkinin miktarı 0,74 olarak, besin içeriğine göre gıda tüketimi davranışı ile porsiyon boyutu tercihi arasındaki ilişkinin miktarı 0,69 olarak gözlenmiştir ve bu ilişkilerin anlamlı olduğu bulunmuştur $(\mathrm{p}<0,05)$.

Tablo 4. Uyum İndeksi Kriterlerine Ait Değerler

\begin{tabular}{|c|c|c|}
\hline Uyum Kriterleri & Mükemmel Uyum & Kabul Edilebilir Uyum \\
\hline
\end{tabular}


İ. Ayar 11/1 (2019) 545-557

\begin{tabular}{|c|c|c|}
\hline$\chi 2 / \mathrm{sd}$ & $\leq 3$ & $\leq 5$ \\
\hline RMSEA & $0<\mathrm{RMSEA}<0.05$ & $0.05 \leq \mathrm{RMSEA} \leq 0.10$ \\
\hline RMR & $0 \leq \mathrm{SRMR}<0.05$ & $0.05 \leq \mathrm{SRMR} \leq 0.10$ \\
\hline SRMR & $0 \leq \mathrm{SRMR}<0.05$ & $0.05 \leq \mathrm{SRMR} \leq 0.10$ \\
\hline NFI & $0.95 \leq \mathrm{NFI} \leq 1$ & $0.90 \leq \mathrm{NFI} \leq 0.95$ \\
\hline NNFI & $0.95 \leq \mathrm{NNFI} \leq 1$ & $0.90 \leq \mathrm{NNFI} \leq 0.95$ \\
\hline CFI & $0.95 \leq \mathrm{CFI} \leq 1$ & $0.90 \leq \mathrm{CFI} \leq 0.95$ \\
\hline GFI & $0.95 \leq \mathrm{GFI} \leq 1$ & $0.90 \leq \mathrm{GFI} \leq 0.95$ \\
\hline AGFI & $0.90 \leq \mathrm{AGFI} \leq 1$ & $0.85 \leq \mathrm{AGFI} \leq 0.90$ \\
\hline
\end{tabular}

Tablo 5'te görüldüğ̈̈ üzere yapılan doğrulayıcı faktör analizine ait uyum indeksi kriterlerinin kabul edilebilir uyum indeksi kriterlerini karşıladığı sonucuna ulaşılmıştır.

Tablo 5. Ölçeğin Uyum İyiliği Değerleri

\begin{tabular}{|l|l|l|l|l|l|l|l|l|l|}
\hline $\mathbf{X 2 / d f}$ & $\mathbf{p}$ & RMSEA & CFI & GFI & AGFI & NNFI & NFI & RMR & SRMR \\
\hline 3,364 & 0,000 & 0,076 & 0,94 & 0,92 & 0,89 & 0,93 & 0,92 & 0,089 & 0,056 \\
\hline
\end{tabular}

Tablo 6' da araştırmanın örneklemine ve çalışma grubuna yönelik tanımlayıcı istatistiksel sonuçlar verilmiştir.

Tablo 6. Çalışma Grubuna Yönelik İstatistikler

\begin{tabular}{|l|l|l|l|}
\hline \multicolumn{2}{|l|}{ Özellikler } & f & $\%$ \\
\hline \multirow{3}{*}{ Cinsiyet } & Kadın & 190 & 46,3 \\
\cline { 2 - 4 } & Erkek & 220 & 53,7 \\
\hline \multirow{3}{*}{ Barınma Şekli } & Aile & 194 & 47,3 \\
\cline { 2 - 4 } & $\ddot{O}$ Ŏrenci Evi & 64 & 15,6 \\
\cline { 2 - 4 } & Yurt & 152 & 37,1 \\
\hline \multicolumn{2}{|l|}{ Toplam } & 410 & $\% 100$ \\
\hline
\end{tabular}

Araştırmaya dahil edilen 410 Kişilik örneklemin \%53,7'si erkek, geri kalanı kadındır. Kadın ve erkek oranlarının birbirine yakın olduğu gözlenmiştir. Araştırmaya katılanların \%47,3 ile büyük kısmının ailesi ile birlikte ikamet ettiği sonucuna varılmıştır. Katılımcıların \%37,1'inin yurtta ikamet ettiği, \%15,6'sının ise öğrenci evinde kaldığı tespit edilmiştir.

Katılımcılara beden kitle indeksine göre ideal kilo sınırlarının üzerinde olup olmadıkları sorulmuş, katılımcıların \%36'sının ideal kilolarının üzerinde olduklarını ifade ettikleri sonucuna ulaşılmıştır.

Tablo 7'de katılımcıların cinsiyetlerine göre gıda tercihlerinin farklılaşıp farklılaşmadığını belirlemek üzere yapılan analiz sonuçlarına yer verilmiştir.

Tablo 7. Cinsiyete göre T testi sonuçları

\begin{tabular}{|l|l|l|l|l|l|l|l|}
\hline Faktörler & Cinsiyet & N & Ort. & SS & t & SD & p \\
\hline \multirow{3}{*}{ BंGD } & Kadın & 190 & 2,6884 &, 90019 & $-3,727$ & 408 &, 000 \\
\cline { 2 - 6 } & Erkek & 220 & 3,0300 &, 94662 & & & \\
\hline \multirow{3}{*}{ KKD } & Kadın & 190 & 3,2211 &, 96866 & $-2,653$ & 408 &, 008 \\
& Erkek & 220 & 3,4614 &, 86549 & & & \\
\hline \multirow{3}{*}{ PB } & Kadın & 190 & 2,7316 &, 96066 & $-2,336$ & 408 &, 020 \\
\cline { 2 - 5 } & Erkek & 220 & 2,9515 &, 94156 & & & \\
\hline YYD & Kadın & 190 & 2,4868 &, 99793 &, 378 & 408 &, 705 \\
\cline { 2 - 5 } & Erkek & 220 & 2,4500 &, 97092 & & & \\
\hline
\end{tabular}

Katılımcıların cinsiyetlerine göre gıda tercihlerinin farklılaşıp farklılaşmadığını belirlemek üzere yapılan $\mathrm{t}$ testi sonuçlarına göre, tablo 7 'de görüldüğü üzere "besin içeriğine göre gıda tüketimi davranışı", "kilo kontrolü davranışı" ve "porsiyon boyutu tercihi" boyutlarında tüketicilerin tutumlarının cinsiyete göre 
değiştiği $(\mathrm{p}<0,05)$, ancak "yemek yeme davranışı" boyutunda anlamlı bir farklılığın olmadığı sonucuna ulaşılmıştır $(p>0,05)$. Bu durumda $\mathrm{H} 1$ hipotezi 3 boyut için kabul edilirken, 1 boyut için kabul edilmemiştir.

Tablo 8'de katılımcıların barınma durumlarına göre gıda tercihlerinin farklılaşıp farklılaşmadığını belirlemek üzere yapılan analiz sonuçlarına yer verilmiştir.

Tablo 8. Barınma Durumlarına Göre Anova Testi Sonuçları

\begin{tabular}{|c|c|c|c|c|c|c|c|}
\hline \multicolumn{2}{|c|}{ Faktörler } & $\mathbf{N}$ & Ort. & SS & Sd & $\mathbf{F}$ & $\mathbf{p}$ \\
\hline \multirow[t]{4}{*}{ BİGD } & Aile & 194 & 2,8330 & ,99102 & \multirow[t]{4}{*}{$2-407$} & \multirow[t]{4}{*}{1,673} & \multirow[t]{4}{*}{,189 } \\
\hline & Öğrenci Evi & 64 & 3,0688 & ,90306 & & & \\
\hline & Yurt & 152 & 2,8382 & ,88182 & & & \\
\hline & Toplam & 410 & 2,8717 & ,93987 & & & \\
\hline \multirow[t]{4}{*}{ KKD } & Aile & 194 & 3,2796 & ,88457 & \multirow[t]{4}{*}{$2-407$} & \multirow[t]{4}{*}{5,208} & \multirow[t]{4}{*}{,006 } \\
\hline & Öğrenci Evi & 64 & 3,6875 & ,94176 & & & \\
\hline & Yurt & 152 & 3,2977 & ,93397 & & & \\
\hline & Toplam & 410 & 3,3500 & ,92146 & & & \\
\hline \multirow[t]{4}{*}{ PB } & Aile & 194 & 2,7784 & ,95471 & \multirow[t]{4}{*}{$2-407$} & \multirow[t]{4}{*}{9,088} & \multirow[t]{4}{*}{,000 } \\
\hline & Öğrenci Evi & 64 & 3,3073 & ,96738 & & & \\
\hline & Yurt & 152 & 2,7478 & ,90131 & & & \\
\hline & Toplam & 410 & 2,8496 & ,95562 & & & \\
\hline \multirow[t]{4}{*}{ YYD } & Aile & 194 & 2,3325 & 1,03013 & \multirow[t]{4}{*}{$2-407$} & \multirow[t]{4}{*}{4,234} & \multirow[t]{4}{*}{,015 } \\
\hline & Öğrenci Evi & 64 & 2,7109 & 1,03435 & & & \\
\hline & Yurt & 152 & 2,5362 & ,87099 & & & \\
\hline & Toplam & 410 & 2,4671 & ,98249 & & & \\
\hline
\end{tabular}

Katılımcıların barınma durumlarına göre gıda tüketimi tercihlerinin değişip değişmediğini belirlemek üzere yapılan Anova testi sonuçları bakıldığında, Tablo 8'de görüldüğü üzere; "kilo kontrolü davranışı", "porsiyon boyutu tercihi" ve "yemek yeme davranışı" boyutlarında tüketicilerin gıda tercihlerinin barınma durumlarına göre değiştiği $(p<0,05)$, "besin içeriğine göre gıda tüketimi davranışı" boyutunda ise değişmediği sonucuna ulaşılmıştır ( $p>0,05)$. Buna göre H2 hipotezi "besin içeriğine gida tüketimi davranışı" boyutu için kabul edilmezken, diğer boyutlar için kabul edilmiştir.

Tablo 9'da katılımcıların beden kitle indeksine göre ideal kilo sınırlarının üzerinde olup olmama durumlarına göre gıda tercihlerinin farklılaşıp farklılaşmadığını belirlemek üzere yapılan analiz sonuçlarına yer verilmiştir.

Tablo 9. Kilo Durumuna Göre Analiz Sonuçları

\begin{tabular}{|c|c|c|c|c|c|c|c|}
\hline Faktörler & Cinsiyet & $\mathbf{N}$ & Ort. & SS & $\mathbf{t}$ & SD & $\mathbf{p}$ \\
\hline \multirow[t]{2}{*}{ BİGD } & Evet & 147 & 2,8245 & ,98172 & \multirow[t]{2}{*}{,- 760} & \multirow[t]{2}{*}{408} & \multirow[t]{2}{*}{,448 } \\
\hline & Hayır & 263 & 2,8981 & 91649 & & & \\
\hline \multirow[t]{2}{*}{ KKD } & Evet & 147 & 3,2687 & 98059 & \multirow[t]{2}{*}{$-1,337$} & \multirow[t]{2}{*}{408} & \multirow[t]{2}{*}{, 182 } \\
\hline & Hayır & 263 & 3,3954 & ,88537 & & & \\
\hline \multirow[t]{2}{*}{$\mathrm{PB}$} & Evet & 147 & 2,9388 & 1,11036 & \multirow[t]{2}{*}{1,414} & \multirow[t]{2}{*}{408} & \multirow[t]{2}{*}{,158 } \\
\hline & Hayır & 263 & 2,7997 & ,85533 & & & \\
\hline \multirow[t]{2}{*}{ YYD } & Evet & 147 & 2,4320 & 1,05116 & \multirow[t]{2}{*}{,- 540} & \multirow[t]{2}{*}{408} & \multirow[t]{2}{*}{,589 } \\
\hline & Hayır & 263 & 2,4867 & ,94345 & & & \\
\hline
\end{tabular}

Katılımcıların kilo durumlarına göre gıda tercihlerinin farklılaşıp farklılaşmadığını belirlemek üzere yapılan t testi sonuçlarına göre, Tablo 9'da görüldüğü üzere, tüm faktör gruplarında anlamlı farklılığa rastlanmamıştır ( $>>0,05)$. Buna göre $\mathrm{H} 3$ hipotezi tüm boyutlar için kabul edilmemiştir.

\section{Sonuç ve Tartışma}

Günümüzde yaşam kalitesini iyileştirmenin, yeni tıbbi tedavi yöntemleri ve ilaçlardan daha çok yaşam tarzımızdaki davranış değişikliklerinden (daha iyi beslenme ve daha fazla egzersiz gibi) geçtiği sonucu pek çok çevre tarafından kabul görmektedir. Bunun aksine artan iş yükü, stres faktörleri, çalışma yaşamındaki 
değişiklikler, hızlı yaşam tarzları, yiyecek endüstrisindeki gelişmeler ve hızlı tüketime yönelim gibi pek çok faktörle birlikte günümüzde tüm dünyada giderek artan obezite sorunu da oldukça dikkat çekmekte, yeni neslin bu sorunla erken yaşta tanışması ise büyük tedirginliklere sebep olmaktadır. Özellikle yiyecek endüstrisindeki değişimler ve rekabet ortamı, bireyleri daha fazla tüketime yönlendirmektedir. Bireyler sunulan ürün çeşitliliği ve bolluğu karşısında, artık güvendikleri yiyecekleri tüketmek yerine daha ucuz ve daha büyük porsiyonlarla sunulan gıda ürünlerine yönelmektedirler.

İlk çağlardan beri insanlar aslında hangi yiyecekleri tüketecekleri ve ne kadar tüketeceklerine, yedikleri yiyecekleri tüketmenin güvenli olup olmadığına inanıp inanmadıklarına bağlı olarak karar vermişlerdir. İlk çağlarda tatlı meyve ve sebzeleri yemenin muhtemelen güvenli olduğu ve tadı kötü olanların muhtemelen güvensiz olduğuna inanarak, yine iyi kokan yiyeceklerin yenilebilir, ancak kötü kokanların yenilemez olduğunu düşünerek tüketimlerini gerçekleştirmişlerdi. Günümüzde ise artık insanlar yiyecek ve içecekleri tüketirken etiketleme yoluyla bilgi edinmektedirler. Bu etiketler bir taraftan besin içerikleri hakkında bilgi sunarken, diğer taraftan çeşitli kuruluşlar tarafından yapılmış denetleme sonuçlarını da içermektedir. Aslında insanlar kendileri için güvenli olan yiyecekleri daha kolay ayırt edebilir hale gelmişlerdir. Ancak herkesin gıda ürünleri satın alma ve tüketiminde bu etiketleme ve bilgi sağlayıcılarını aynı oranda dikkate aldığı ve önemsediğini söylemek mümkün değildir. Kimi insan yedikleri yiyeceklerle ilgili ayrıntıları öğrenmek için meşgul olurken kimi dikkate bile almamaktadır. Önceki araştırmalar, özellikle üniversite çağındaki gençlerin, gıda seçimlerinde göreceli olarak sağlıklarına dikkat etmediklerini göstermektedir (Spear, 2002; Lytle, 2002; Lone vd., 2009).

$\mathrm{Bu}$ araştırmada üniversite öğrencilerinin gıda seçim tercihleri nicel araştırma yöntemlerinden anket tekniği ile ortaya konmuştur. Araştırmada elde edilen sonuçlar şu şekilde özetlenebilir;

- Katılımcıların yemek yeme davranışları ile kilo kontrolü davranışı arasındaki ilişkinin miktarı 0,62 olarak bulunmuştur. Öğrencilerin yemek yeme alışkanlıkları ile diyet ve kilo kontrolü davranışları arasında anlamlı bir ilişki vardır. Ne yediğinin farkında olma, bilinçli besin tüketimi alışkanlıkları arttıkça, katılımcıların kilo kontrolü davranışlarının da arttığı sonucuna ulaşılmıştır.

- Katılımcıların yemek yeme davranışları ile besin içeriklerine göre gıda tercihleri arasındaki ilişkinin miktarı 0,60 olarak bulunmuştur. Bu sonuç, öğrencilerin besin içeriklerine yönelik etiket uygulamalarını dikkate alma durumlarının, ne yediğinin farkında olma ve bilinçli besin tüketimi alışkanlıkları ile doğru orantılı olarak değiştiğini göstermektedir.

- Yine katılımciların yemek yeme davranışları ile porsiyon boyutu tercihleri arasında istatistiksel olarak 0,65 oranında anlamlı ilişki bulunmuştur. Bu sonuç ise, ne yediğinin farkında olma ve bilinçli besin tüketimi alışkanlıklarının porsiyon boyutu tercihleri ile ilişkili olduğunu göstermektedir. Bilinçli besin tüketimi alışkanlığı arttıkça küçük porsiyon boyutlarını tercih etme oranında da artış gözlenmiştir.

- Kilo kontrol davranışı ile besin içeriğine göre gıda tüketimi davranışı arasındaki ilişkinin miktarı 0,71, porsiyon boyutu tercihi arasındaki ilişkinin miktarı 0,74 olarak bulunmuştur. Buna göre, yaşamlarında diyet yönelimli beslenme ve kilo kontrolü davranışlarını sergileyen katılımcıların besin içeriklerini daha çok dikkate aldıkları, porsiyon boyutlarını da dikkate aldıkları sonucuna varılmıştır.

- "Besin içeriğine göre gıda tüketimi davranışı", "kilo kontrolü davranışı" ve "porsiyon boyutu tercihi" boyutlarında tüketicilerin tutumlarının cinsiyete göre değiştiği $(\mathrm{p}<0,05)$ sonucuna ulaşılmıştır. Tüm bu boyutlarda erkek katılımcıların kadın katılımcılardan daha pozitif tutuma sahip oldukları gözlenmiştir.

- "Kilo kontrolü davranışı", "porsiyon boyutu tercihi" ve "yemek yeme davranışı" boyutlarında tüketicilerin gıda tercihlerinin barınma durumlarına göre değiştiği $(p<0,05)$ sonucuna ulaşılmıştır. Öğrenci evinde ikamet eden öğrencilerin daha pozitif tutum sahibi olduğu gözlenmiştir.

Araştırma sonuçlarına dayanılarak aşağıdaki öneriler geliştirilmiştir;

Gıda üreticilerinin ve perakendecilerin okuması ve anlaşılması kolay beslenme etiketlemelerini geliştirmeleri halinde ürünlerini standart beslenme etiketi bulunan ürünlere göre avantajlı kılabilir. Çünkü tüketiciler artık, daha fazla yemek yememe, sağlıklı beslenme, şeker, tuz ve yağ tüketimini azaltma, sağlıklı diyet takip etme, gibi bakımlardan kendilerini sorgular hale gelmişlerdir. Nitekim daha önceki bazı araştırma sonuçları, 
uygun beslenme bilgisi veya sağlik bilgileri sunulduğunda, tüketicilerin ürüne, beslenme tutumlarına ve satın alma niyetlerine karşı daha olumlu tutumlara sahip olduğunu ve kalp hastalığı ve inme risklerinin daha düşük olduğunu algıladıklarını göstermektedir (Kozup vd., 2003).

Hükümetlerin ve diğer sosyal örgütlerin, işletmeler gibi pazarlamama faaliyetlerine daha fazla odaklanmaları gerekmektedir. Devletin tütün ve alkolde olduğu gibi diğer sağlıksız ürünlerin tüketimini de caydırmaya çalışması gibi. Bu konudaki araştırmalar, özellikle çocukların yiyecek ve içecek reklamcılığına maruz kaldıklarını ve mevcut düzenleyici sistemin çocukları yağ, şeker ve sodyum gibi gıda pazarlamasından korumakta başarısız olduklarını göstermektedir. Özellikle belli bir yaşın altındaki gençlere sağllksız gıda ürünleri yerine ikame ürünler sunulabilir. İşletmelerin yanı sıra devlet ve diğer örgütler sağlıklı olanı teşvik edici uygulamaları gerçekleştirilebilir. Gerekirse bu konuda danışmanlık birimleri kurulabilir.

Sigara içilebilecek yerlerin veya alkol kullanılabilecek- satın alınabilecek yerlerin ve zamanın kısıtlanmasında olduğu gibi sağlıksız olarak nitelendirilebilecek gıda ürünlerine ulaşım kontrol altına alınabilir. Örneğin, okul kantinlerinde ya da çocukların daha çok bulunduğu mekanlarda fastfood tarzı ürünlerin bulundurulmaması, yerine sağlıklı ürünlerin bulundurulması gibi.

Devletin ve diğer toplum kuruluşlarının sağlıksız gıda ürünlerinin reklam ve diğer tutundurma faaliyetlerini kontrol altına alması gerekmektedir. Aynı şekilde sağlıksız gıda ürünlerinin zararlarını insanlara iletişim faaliyetleriyle aktararak demarketing stratejilerini uygulamaları gerekmektedir. Fiyatlama kararları bakımından sağlıksız gıda ürünlerinin fiyatlarına müdahaleler yapılabilir. Tütün ve alkol ürünlerinden alınan vergilerin artırılması ile ürünlerin fiyatının yükseltilmesinde olduğu gibi fast food ürünlerinde özellikle çocukları satın almaktan caydıracak fiyatlama uygulamaları gerçekleştirilebilir.

Gençlerin sağlıklı gida tüketim tercihlerinin belirlenmesi üzerine özellikle ülkemizde nicel ve nitel yöntemlerin bir arada kullanıldığı karma çalışmalara ihtiyaç vardır. Bu nedenle araştırma sonuçları ileriki çalışmalara yol gösterici olabilir.

\section{Kaynaklar}

Altınay, A., ve Sert, S. (2012). Pazarlasak da mı Satsak Pazarlamasak da mı Satsak?, Pazarlamada Yeni Bir Boyut: De-Marketing (Pazarlamama) Kavramı. Sosyal ve Beşeri Bilimler Dergisi, (1), 67-73.

Baporikar, N., and Fotolela, R. (2017). Demarketing Tobacco Products Strategy to Impact Customers for Social Change. International Journal of Civic Engagement and Social Change (IJCESC), 4(4), 16-30. doi:10.4018/IJCESC.2017100102

Barbara, J. (2008). Demarketing of Tobacco Products and Consumers Behavior Formation. Contemporary Economics, 2(1), 1-178.

Beeton, S., and Benfield, R. (2002). Demand control: The case for demarketing as a visitor and environmental management tool. Journal of Sustainable Tourism, 10(6), 497-513.

Bourdeau, B. L., Brady, , M., and Cronin Jr., J. (2006). A new frontier in the battle against smoking: An exploratory investigation of low-income adult smokers. Journal of Nonprofit ve Public Sector Marketing, 16(2), 123-149.

Bozacı, İ. (2016). Seçici Pazarlamama (Demarketing) Algılamaları İle Müşteri Tutumları İlişkisi: Genç Tüketiciler İle Gerçekleştirilen Bir Saha Çalışması. Uluslararası Sosyal Araştırmalar Dergisi, 43(9), 25482556.

Cintrón, Q., Hack, V., Rivera, P., Velázquez, M. and Pellot, D. (2017). The Evolution of Demarketing Literature. Fórum Empresarial, 22(1), 77-108.

Cui, G., and Choudhury, P. (2003). Demarketing of health services. The Journal of Consumer Affairs, 37(2), 364387.

Elliott, C. (2017). Knowledge needs and the 'savvy' child: teenager perspectives on banning food marketing to children. Critical Public Health, 27(4), 430-442. 


\section{İ. Ayar 11/1 (2019) 545-557}

Folkvord, F., Anschütz, D., Buijzen, M., and Valkenburg, P. (2015). The effect of playing advergames promoting energy-dense snacks or fruit on actual food intake among children. The American Journal of Clinical Nutrition, 239 - 245.

Freeman, B., Kelly, B., Vandevijvere, S., and Baur, L. (2016). Young adults: Beloved by food and drink marketers and forgotten by public health?, Health Promotion International, 31, 954-961.

Gallopel-Morvan, K., Jacques, O., Mathias, W., and Pino, J. (2012). Demarketing tobacco products : the influence of plain packs on smokers and non-smokers perceptions and behavioural intentions. Journal de gestion et d'économie médicales, vol. 30(5), 322-331. doi:10.3917/jgem.125.0322.

Gundlach, G. T., Bradford, K. D., and Wilkie, W. L. (2010). Countermarketing and Demarketing Against Product Diversion: Forensic Research in the Firearms Industry. Journal Of Public Policy ve Marketing, 29(1), 103-122.

Haq, F., Medhekar, A., and Ferdous, , T. (2011). Health Literacy for Muslim Consumers: A Strategic Demarketing Approach. Journal of Global Intelligence ve Policy, 4(4), 54-66.

Hassan, L. M., Shiu, E., Walsh, G., and Hastings, G. (2009). Help-for a life without tobacco: A case study on demarketing across two levels. Marketing Intelligence ve Planning, 27(4), 486-502.

Inness, M., Barling, J., Rogers, K., and Turner, N. (2008). De-marketing tobacco through price changes and consumer attempts to quit smoking. Journal of Business Ethics, 77(4), 405-416.

Kotler, P., and Levy, S. (1971). Demarketing, Yes, Demarketing. Harvard Business Review, 79(1), 74-80.

Kozup, J.C., Creyer E. H., and Burton, S. (2003). Making Healthful Food Choices: The Influence of Health Claim and Nutrition Information on Costumer Evaluation of Packaged Food Product and Restaurant Menu Items. The Journal of Marketing, 67 (2), 19-34.

Lee, D., Cutler, B. D., and Burns, J. (2004). The marketing and demarketing of tobacco products to lowincome African-Americans. Health Marketing Quarterly, 22(2), 51-68.

Lefebvre, R. C, and Kotler, P. (2011). Design thinking, demarketing and behavioral economics: Fostering interdisciplinary growth in social marketing. In G. Hastings, K. Angus, ve C. A. Bryant (Eds.), The Sage handbook of social marketing (pp. 80-94). Los Angeles, CA: Sage Publications Ltd

Lepisto, L. R. (1983). Demarketing strategies: Assessment and implementation. The Mid-Atlantic Journal of Business, 22(1), 31-41.

Lone, T. A., Pence, D., Levi, A., Chan, K., and Bianco-Simeral, S. (2009). Marketing healthy food to the least interested consumers. Journal of Foodservice, 20(2), 90-99.

Lytle, L. (2002). Nutrition Concerns of the Adolescents. Journal of American Dietetics Association, 102, 8-12.

Memiş, S. (2017). Pazarlamama kavramı ve uygulamadaki bazı örnekler. Uluslararası Sosyal Araştırmalar Dergisi, 10(50), 770-775.

Moore, R. S. (2005). The sociological impact toward smoking: Secondary effects of the demarketing of smoking. The Journal of Social Psychology, 145(6), 703-718.

Mucuk, İ. , (2001). Pazarlama İlkeleri, İstanbul, Türkmen Kitabevi.

Nelson M. C., Story M., Larson N. I., Neumark-Sztainer D., and Lytle L. A. (2008) Emerging adulthood and college-aged youth: an overlooked age for weight-related behavior change. Obesity, 16, 2205-2211.

Onaran, B. (2017). Sürdürülebilirlik ve Pazarlama İlişkisi ve Pazarlama Stratejisinin Bu İlişkideki Yeri. Researcher: Social Science Studies, 9(5), 30-40.

Post, J. E., and Baer, E. (1979). Demarketing infant formula: Consumer products in the developing world. Journal of Contemporary Business, 7(4), 17-35.

Salem, M. Z. (2010). Factors affecting the demarketing of smoking in Palestine. Journal of Arab Culture, Management and Sustainable Development, 1(4), 340-358. 
Saunders, M., Lewis, P., and Thornhill, A. (2009). Research Methods for Business Students. London: Prentice Hall.

Scully, M., Dixon, H., and Wakefield, M. (2009). Association between commercial television exposure and fast-food consumption among adults. Public Health Nutrition, 12(1), 105-110.

Spear, B. A. (2002). Adolescent growth and development. Journal of American Dietetic Association, 102(3), 22-25.

Williams, S. (2013). Action needed to combat food and drink companies' social media marketing to adolescents. Perspectives in Public Health, 133, 146-147.

Yang, Z., Schaninger, C., and Laroche, M. (2013). Demarketing teen tobacco and alcohol use: Negative peer influence and longitudinal roles of parenting and self-esteem. Journal Of Business Research, 66(4), 559567. 